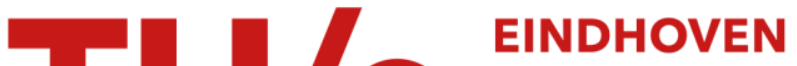

\section{Measurements of sooting tendency in laminar diffusion flames of $n$-heptane at elevated pressure}

\section{Citation for published version (APA):}

Zhou, L., Dam, N. J., Boot, M. D., \& Goey, de, L. P. H. (2013). Measurements of sooting tendency in laminar diffusion flames of n-heptane at elevated pressure. Combustion and Flame, 160(11), 2507-2516.

https://doi.org/10.1016/j.combustflame.2013.05.018

DOI:

10.1016/j.combustflame.2013.05.018

Document status and date:

Published: 01/01/2013

\section{Document Version:}

Publisher's PDF, also known as Version of Record (includes final page, issue and volume numbers)

\section{Please check the document version of this publication:}

- A submitted manuscript is the version of the article upon submission and before peer-review. There can be important differences between the submitted version and the official published version of record. People interested in the research are advised to contact the author for the final version of the publication, or visit the $\mathrm{DOI}$ to the publisher's website.

- The final author version and the galley proof are versions of the publication after peer review.

- The final published version features the final layout of the paper including the volume, issue and page numbers.

Link to publication

\section{General rights}

Copyright and moral rights for the publications made accessible in the public portal are retained by the authors and/or other copyright owners and it is a condition of accessing publications that users recognise and abide by the legal requirements associated with these rights.

- Users may download and print one copy of any publication from the public portal for the purpose of private study or research.

- You may not further distribute the material or use it for any profit-making activity or commercial gain

- You may freely distribute the URL identifying the publication in the public portal.

If the publication is distributed under the terms of Article 25fa of the Dutch Copyright Act, indicated by the "Taverne" license above, please follow below link for the End User Agreement:

www.tue.nl/taverne

Take down policy

If you believe that this document breaches copyright please contact us at:

openaccess@tue.nl

providing details and we will investigate your claim. 


\title{
Measurements of sooting tendency in laminar diffusion flames of n-heptane at elevated pressure
}

\author{
Lei Zhou*, Nico J. Dam, Michael D. Boot, L. Philipus H. de Goey \\ Combustion Technology, Department of Mechanical Engineering, Eindhoven University of Technology (TU/e), P.O. Box 513, 5600 MB Eindhoven, The Netherlands
}

\section{A R T I C L E I N F O}

\section{Article history:}

Received 21 March 2013

Received in revised form 14 May 2013

Accepted 17 May 2013

Available online 11 June 2013

\section{Keywords:}

Laminar diffusion flame

Soot formation

n-Heptane

Elevated pressure

Laser diagnostics

\begin{abstract}
A B S T R A C T
This research focuses on the effects of an increasing pressure on the soot formation during combustion of vaporized liquid fuel. Therefore soot formation is measured in a laminar diffusion flame, with n-heptane as fuel, over a range of pressures from 1.0 to 3.0 bar. The soot volume fraction in the diffusion flames has been measured using Laser-Induced Incandescence (LII) calibrated by means of the Line Of Sight Attenuation (LOSA) technique. The values of the calibration factors between LII intensities and soot volume fraction from LOSA are slightly varied for different pressure. The integral soot volume fractions show power law dependence on pressures, being proportional to $p^{n}$, with $n$ being $3.4 \pm 0.3$ in the pressure range of 1.0-3.0 bar.
\end{abstract}

(C) 2013 The Combustion Institute. Published by Elsevier Inc. All rights reserved.

\section{Introduction}

Soot emissions from combustion of hydrocarbons have long been recognized as a significant problem to the environment and to the health of humans and other animals.

The understanding of the fundamental mechanism of soot formation has grown considerably by studies on laminar flames. Most literature has reported on soot formation in laminar flames at atmospheric pressure. It is well known that increased pressure has a large influence on the soot production in spray combustion, in premixed as well as diffusion flames [1-3]. Fuel pyrolysis and soot nucleation are enhanced by pressure, and the net effect is that soot growth and concentration are strongly affected by the system pressure $[4,5]$.

Gülder's group at the University of Toronto has been focusing on soot formation research in laminar flame at elevated pressure for many years [6-10]. The soot formation which was defined as the mass flow of soot at a given flame height per unit of carbon mass flow in the fuel, in co-flow methane-air and ethane-air laminar diffusion flames at elevated pressures was measured at different fuel flow rates. Moreover, they reported on the exponential relationship between soot volume fraction and pressure or the fraction of fuel carbon converted soot. Their measurement methods mainly involve Spectral Soot Emission (SSE) and Line-Of-Sight Attenuation (LOSA), to provide information on spatially resolved soot volume fraction as well as temperature, for various fuels

\footnotetext{
* Corresponding author. Fax: +31 402433445.

E-mail address: L.Zhou@tue.nl (L. Zhou).
}

(methane, ethane, ethylene and propane), and pressure increasing from atmospheric to 60 bar. In a recent study [11], the authors summarized that the available high-pressure soot yield data from gaseous fuel diffusion flames behave in a unified way on reduced pressure when the soot yield is properly scaled. However, these studies have definitely addressed the issue of soot formation by gaseous fuels only. For liquid fuels, there is a clear scarcity of data.

Roberts' group at North Carolina State University also conducted a comprehensive investigation of soot formation in laminar flames [12]. Their results are expressed in terms of the Smoke Point Height by measuring the height of a laminar diffusion flame prior to emitting smoke, and in terms of soot volume fraction obtained by Laser Induced Incandescence (LII) with a calibration accomplished by LOSA. Similar to Gülder, only gaseous fuels, such as ethylene and methane, have been studied in their laminar flames over an ambient pressure range from 1 to 25 bar.

Smooke et al. at Yale University also investigated the soot formation in ethylene laminar diffusion flames [13]. The main purpose of their work was to provide quantitative and detailed data for the validation of numerical simulations. Therefore, the flame they studied was relatively simple (ethylene flame under atmospheric conditions), and the measurement method, a combination of LII and LOSA, was quantitative.

Recently, a new study on soot measurements in laminar diffusion flames of liquid fuels has been presented by Menon from Pennsylvania State University [14,15]. An experimental study on the effects of the addition of $m$-xylene to a nitrogen-diluted ethylene flame was presented [14]. A special setup for vaporizing liquid $\mathrm{m}$-xylene introduced as an additive into a flow of gaseous fuels has 
been designed and used in this research. It was used to administer well defined quantities of $m$-xylene to the flame. Stable flames doped with m-xylene at low concentration levels were established at pressures of up to 5 bar. Although it is the first study of quantitative soot volume fraction measurements reporting on a liquid fuel ( $m$-xylene) diffusion flame at high pressure, this research is limited to very small quantities of liquid fuel dopant (at most $5.0 \%$ ) in a gaseous fuel flow.

Actually, there is no data on the sooting behavior of liquid fuel laminar diffusion flames at elevated pressures [16]. However, many practical combustion devices, such as internal combustion engines and gas turbines, operate on liquid fuels at high pressures. In our research, the soot formation in laminar diffusion flames of pure n-heptane up to 3 bar will be discussed.

One of the main challenges for measurements on flames in a closed chamber is the instability of the laminar flame itself. Laminar co-flow flames realized in experimental setups are required to be stable for a period long enough to apply the measurement techniques proposed. This challenge is greatly increased when working at elevated pressures. Several problems were faced by Thomson and co-workers $[4,6]$ when stabilizing methane-air diffusion flames. Darabkhani provides extensive discussions on the stability of laminar diffusion flames $[17,18]$. Experiments were conducted in a high-pressure burner to investigate the influence of pressure (1-16 bar), fuel type (ethylene, methane and propane) and fuel flow rate on the shape and buoyancy induced instabilities in sooty co-flow diffusion flames [18]. The results show that the shape of the flame changes dramatically with increasing pressure, and the instability behavior of the flame depends on both fuel type and pressure. Again, all of this research was conducted on flames with gaseous fuels.

Unfortunately, as compared to flames of gaseous fuels, the instability of laminar diffusion flames of liquid fuels turns out to be more pronounced, especially at elevated pressures. That is probably the main reason why data on the sooting behavior of liquid fuels in laminar diffusion flames at elevated pressure are not available [16]. Apart from the factors governing the instability of the flames of gaseous fuels $[4,6,17,18]$, some obstacles particular to laminar flames of liquid fuels make the realization of stable flames particularly difficult. In fact, it is difficult to produce stable flames of liquid fuels even at atmospheric conditions, mainly because the homogeneity of the temperature in the whole system is not easy to maintain during the measurement process, which in turn could bring about incomplete evaporation of the liquid fuel or condensation of the pre-vaporized liquids in the fuel line towards the burner.

Consequently, a specially designed burner and fueling system are proposed in this paper, which significantly improve the homogeneity of the temperature of the whole fuel line of pre-vaporized liquid fuels. The stability range of the flames is extended up to 3 bar.

It is important to develop diagnostic methods for soot formation measurements which can work under elevated pressure. Generally, as already mentioned in the previous part, two main methods have been used for soot detection: a luminescence method, called Laser-Induced Incandescence (LII) and an extinction method, called Line Of Sight Attenuation (LOSA).

LOSA is a widely used diagnostic method for the quantification of soot volume fractions in flames. Its principle is straightforward. The optical transmissivity of the flame of interest is determined from the difference in intensity of a narrow laser beam that has or has not passed through the flame. This yields the total extinction coefficient, integrated along the whole path of the laser beam through the flame. Typically, this "line of sight" corresponds to a tangential path, at a fixed height above the burner exit $(\mathrm{HAB}=$
Height Above Burner). From a series of measurements at various lateral positions at the same $\mathrm{HAB}$, the radial soot distribution can be reconstructed. By also varying the $\mathrm{HAB}$, the whole 3-D soot volume fraction field can be derived. Performed in this way, this method relies on several assumptions. The flame must be stable during the whole measurement series, and it must be axis-symmetric in order to reconstruct the radial distributions at fixed HAB (this involves an inverse Abel transform). Finally, the method requires an independent calibration or knowledge on the optical properties of the soot responsible for the attenuation, and it assumes that soot is really the only cause of attenuation.

Laser-Induced Incandescence (LII) is an imaging diagnostic technique, that is based on recording the grey-body radiation of soot that is instantaneously heated to far above the local flame temperature by means of a short laser pulse. Comprehensive overviews of the technique and the physics involved have been given by Schulz et al. [19] and by Michelsen [20]. The incandescence yield is nearly, but not quite, proportional to the local soot volume fraction [21]. This technique provides the advantage of instantaneous $2 \mathrm{D}$ measurement, but requires a calibration (often obtained by LOSA) to yield absolute soot volume fractions [22].

Compared to LOSA, the most important advantage of LII is that it is capable of providing 2D images of the soot distribution directly. However, there are a few limitations. According to research by Bassi et al. [23], at high pressure the soot particle density may be so high that the infrared radiation is not able to penetrate the flame. Incandescence trapping by flame regions in between the probe volume and the detector is a concern in highly sooting flames and may cause an underestimation of the actual soot volume fraction [24]. Shaddix and Smyth [25] claims that signal trapping becomes significant at soot volume fractions above $10 \mathrm{ppm}$. Liu et al. [26] used the uncorrected LII intensities and the particle temperatures derived from wavelength dependent LII intensity ratios and argued that the soot volume fraction inferred from the absolute LII intensity technique is higher than the true value, especially when the detection location is on the flame centerline and the soot loading is high. Thus, he claims that a correction for signal trapping in general is difficult, if not impossible, since it requires knowledge not only on the distribution of the soot volume fraction, but also on the morphology of soot particles.

Accordingly, at present there is no broadly accepted model to extract soot volume fractions directly from LII data. Consequently, some researchers prefer a qualitative comparison by comparing relative LII signal intensities [27]. Alternatively, in order to take advantage of LII for 2D soot measurements, as a compromise, some investigations have been accomplished by a combination of LII and LOSA [12-15,23,25,28]. According to this method, one flame will be measured using both methods in otherwise completely similar configurations, and the soot volume fraction of the flame is calculated from the LOSA signals. By means of this process, a calibration factor between LII intensity and LOSA soot volume fraction will be established. As a result, the LII intensity can subsequently be interpreted in terms of the soot volume fraction.

In LOSA, the soot particles are considered to be in the early stage of soot formation and small enough to warrant the Rayleigh assumption [4]. The soot volume fraction $f_{v}$ can be calculated from [4]:

$f_{v}=\frac{\lambda}{k_{e}} K_{e x t}$

where $\lambda$ is the wavelength of the laser, $K_{\text {ext }}$ is experimental extinction coefficient and $k_{e}$ is the dimensionless extinction coefficient. $K_{\text {ext }}$ can be calculated by measuring the transmitted light intensity $I_{T}$, the incident light intensity $I_{0}$ and the affective absorption length $L$ in the flame: 
$K_{e x t}=\frac{1}{L} \ln \frac{I_{0}}{I_{T}}$

According to Eq. (1), the soot volume fraction calculation by LOSA also depends on the value of dimensionless extinction coefficient $k_{e}$ [29]:

$k_{e}=6 \pi\left(1+\alpha_{s a}\right) E(m)$

in which, $E(m)$ is known as the dimensionless refractive index function, $m$ is the complex soot refractive index, which is related to laser parameters, burner parameters, properties of soot, and so on, and $\alpha_{s a}$ is an empirical factor which relates to the morphology of soot. Some researchers tried to estimate values for $m$ and $\alpha_{s a}$. In Thomason's report [4] $E(m)=0.258$ at $\lambda=577 \mathrm{~nm}$ and $\alpha_{s a}=0.05 \pm 0.05$; In Gülders' research [6], $E(m)$ is 0.274 . However, more researchers on the applied investigation of soot measurements prefer to choose a simplified method to estimate $k_{e}$ directly. In Krishnan's reports [30,31], the authors provide some recommendations for $k_{e}$ for a few frequently used fuels, which have been directly used by other researchers [12-15]. In our research, the soot formation in laminar diffusion flames of n-heptane will be measured over the pressure range from atmospheric up to $3 \mathrm{bar}$, so the effect of pressure on the LII calibration factor should be taken into account. According to Hoffmann et al. [32], pressure has little effect on the LII calibration factor when calibrated using laser extinction. Therefore, the extinction coefficient adopted for this research will be $k_{e}=9[30,31]$.

In summary, over the last three decades, various researchers reported investigations on soot formation in laminar flames with gaseous fuels from atmospheric to elevated pressures up to 60 bar. However, it is hard to find any data on soot measurements in laminar diffusion flames with liquid fuels even in atmospheric environments, let alone measurements at elevated pressure, which would be of direct practical relevance for engine combustion. Although the measurement methods, LOSA and LII have been widely discussed, liquid fuels almost never have been used for these measurements. In the present paper, we will provide soot formation data on laminar diffusion flames of n-heptane in the pressure range up to 3 bar by means of LII, with LOSA calibration.

\section{Materials and methods}

\subsection{High Pressure Vessel and Burner (HPVB)}

The goal of the HPVB [33] setup is to conduct research on high pressure combustion processes burning gaseous as well as liquid fuels. The device is illustrated in Fig. 1a. The inner and outer diameters of the fuel tube are $4 \mathrm{~mm}$ and $6 \mathrm{~mm}$, respectively. The inner diameter of the concentric co-flow tube, through which the oxidizer stream flows, is equal to $50 \mathrm{~mm}$ and the height of the burner, from the bottom to the top of the co-flow compartment is $100 \mathrm{~mm}$. The (interchangeable) fuel nozzle is tapered both inside and outside to reduce the formation of turbulent eddies in the air and fuel flow. Sintered metal porous disks are used in the fuel and oxidizer [34]. Aluminum beads ( $3 \mathrm{~mm}$ diameter) and perforated plates which are also flow guiders are placed in the air stream. The fit of the burner inside the pressure vessel is achieved by clamping the burner in one of the holes of the cubic shaped pressure vessel. In order to efficiently use the space inside the pressure vessel and create a good alignment with the optical ports, the burner is partly placed inside the vessel, while the major part is left outside the vessel.

The robust steel vessel allows for experiments up to 30 bar. Figure $1 \mathrm{~b}$ shows the setup assembly. Liquid fuels have to be vaporized, and to avoid cooling and consequent condensation of this vapor, the burner needs to be heated. This heat is supplied by a heated ring (supplying up to $110 \mathrm{~W}$ ) which is mounted around the burner and is kept at a constant temperature. To enhance this control and to avoid unnecessary heat loss, the heated burner is isolated from the pressure vessel by a thermal insulating PTFE (Teflon) ring. The burner is made of aluminum in order to conduct heat more efficiently from the heated ring into the co-flow. The mass flow of all gaseous flow is controlled by mass flow controllers (Bronkhorst). Ref. [33] provides the details of dimensions of the burner and vessel.

The layout for liquid fuels is shown in Fig. 2. The liquid in the fuel accumulator is pressurized with nitrogen. In the accumulator a membrane divides the liquid and the nitrogen. The flow of pressurized liquid is measured by a liquid mass flow meter and the amount of liquid entering the burner is controlled by a Controlled Evaporator Mixer (CEM) from Bronkhorst. The nitrogen that passes through the CEM is controlled by a Mass Flow Controller (MFC). The vaporized liquid fuels can be delivered at a temperature up to $200^{\circ} \mathrm{C}$. In order to avoid condensation, the vaporized liquid is led to the burner via a heated hose of which the temperature can be set between $20^{\circ} \mathrm{C}$ and $200{ }^{\circ} \mathrm{C}$, while a heated ring is placed around the burner.

The flue gas from the exhaust of the pressure vessel can have a temperature above $200^{\circ} \mathrm{C}$ and was cooled before it passes through the pressure regulator. The pressure regulator of the pressure vessel and the pressure regulator of the liquid fuel accumulator are

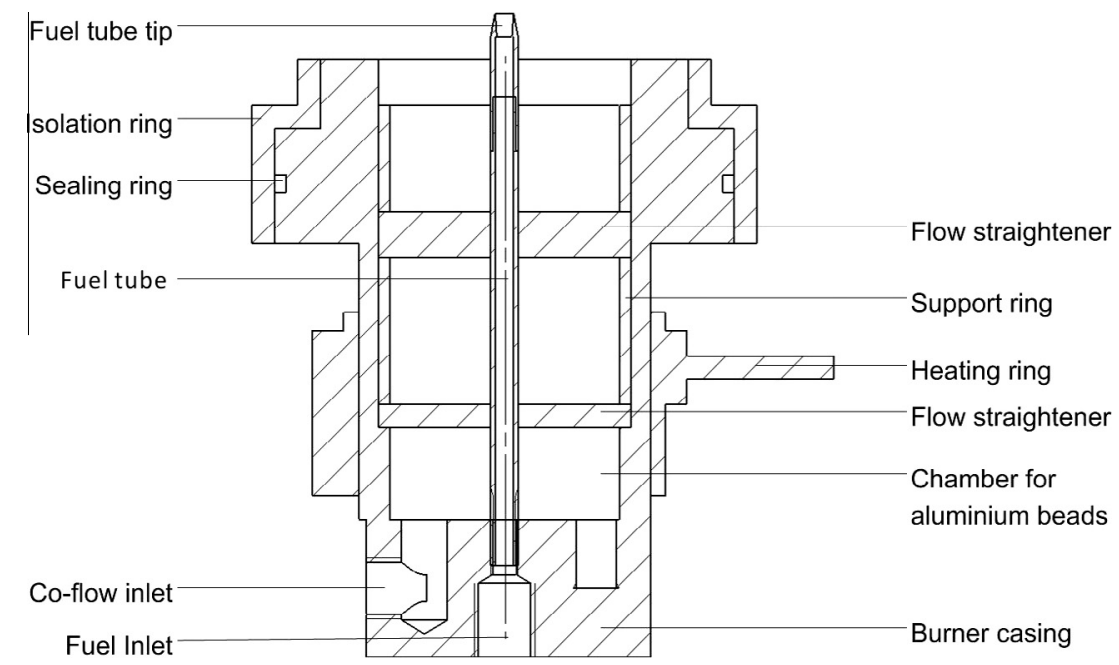

Fig. 1a. A schematic lay-out of the burner [33]. 


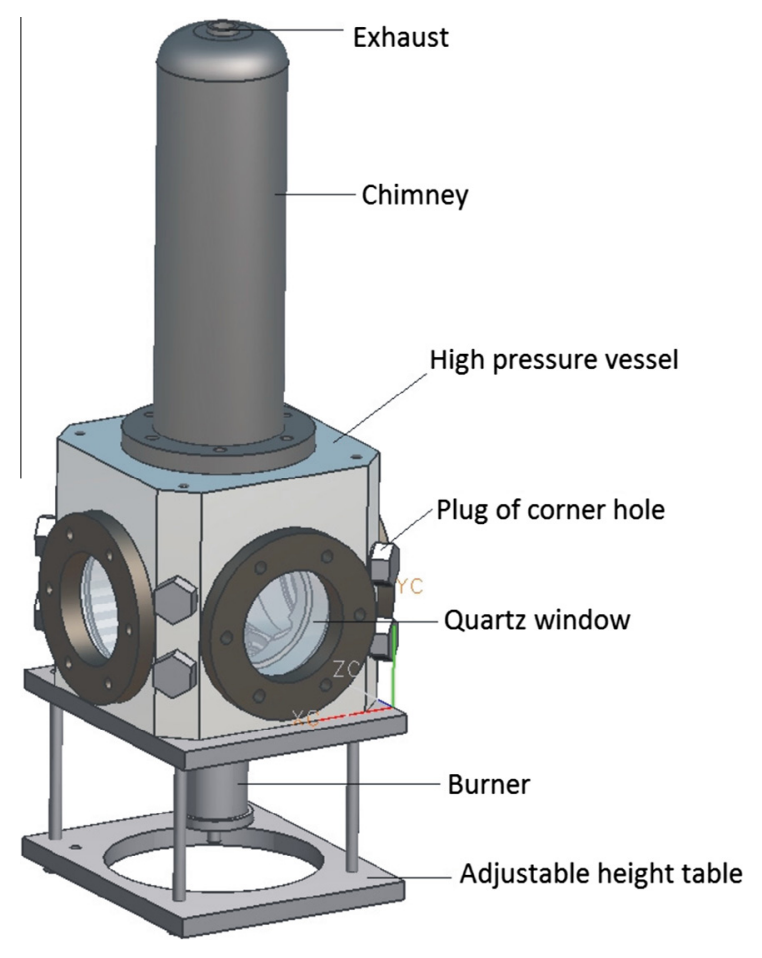

Fig. 1b. Pressure vessel assembly [33].

coupled, in order to keep the pressure in the accumulator at a higher level than the pressure in the vessel.

As a frequently used fuel for flame measurements, n-heptane is chosen as the fuel for this research because its cetane number is close to that of conventional diesel fuels. Moreover, it is one of the primary reference fuels for octane number evaluation. Lastly, it is a representative component for the aliphatic fraction in commercial gasoline and diesel oils.

In order to improve the stability of the laminar diffusion flame of n-heptane, some special design features were implemented. We placed a one-way valve in the fuel line immediately upstream of the burner. The one-way valve forces the flow in one direction and therefore it was also efficient in suppressing oscillatory flow

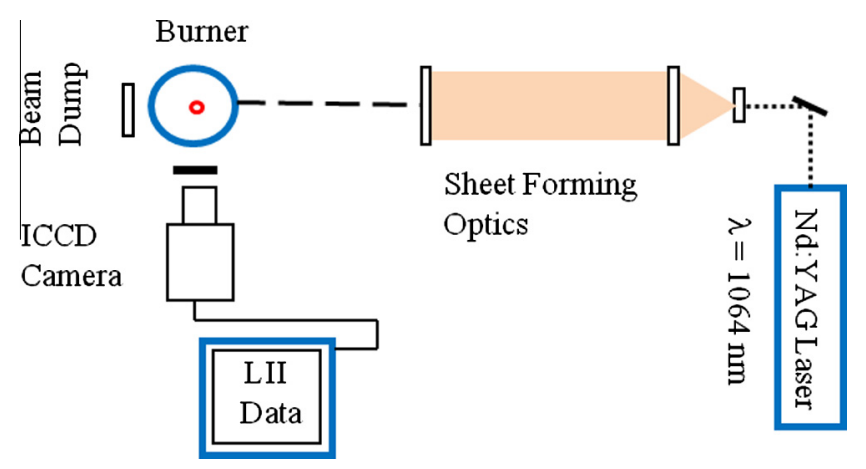

Fig. 3. Layout of the LII set-up.

when the vessel is closed. Another aid to dampen flame oscillations is a buffer vessel of $200 \mathrm{~mL}$ in the fuel line between the heated hose and the burner. This solution showed stability improvements when burning n-heptane at atmospheric pressure. A heating tape is wrapped around the buffer to control the temperature, thereby avoiding condensation.

Flame flickering and oscillations will increase with pressure, but the flame is sufficiently stable for soot measurement in laminar diffusion flames of n-heptane up to 3 bar. Unfortunately, when the pressure exceeds 3 bar, the flame seems to start rotating and pulsating. Further increase in pressure increases these instabilities. The flame rotation speed increases and rotating cells start in the flame base and grow towards the flame tip until they break the flame envelop into sooting tips.

\subsection{LII and LOSA}

The LII experimental setup is shown in Fig. 3. The laser is a Nd:YAG laser (one cavity of a Quntal Brio Twins system) operating at $1064 \mathrm{~nm}$. The energy is fixed at $0.78 \mathrm{~mJ} /$ pulse. The laser fluence is $260 \mathrm{~J} / \mathrm{m}^{2}$, and it is in the linear regime and not saturated. The prompt LII signal was collected by an intensified CCD camera (Princeton Instruments ICCD), using a prompt technique; a gate time of 100 ns was used, with the intensifier at a fixed gain and fully open upon arrival of the laser pulse. The raw LII images were averaged and corrected by subtracting luminescence signals

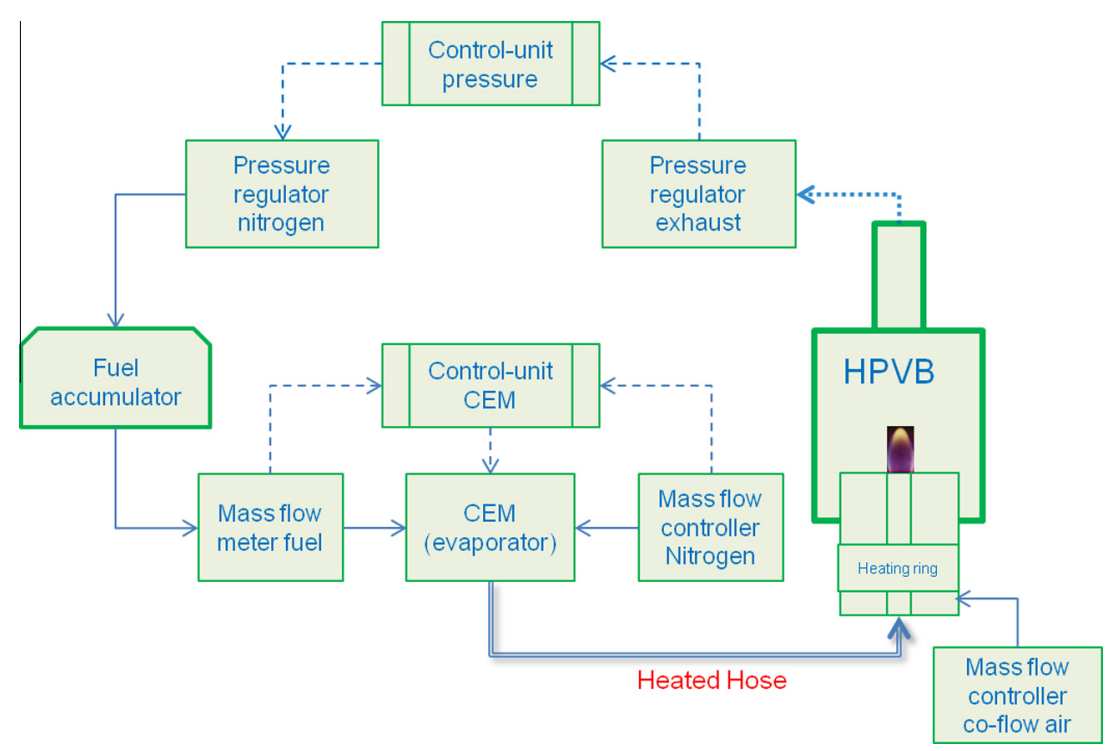

Fig. 2. Layout for liquid fuels system [33]. 


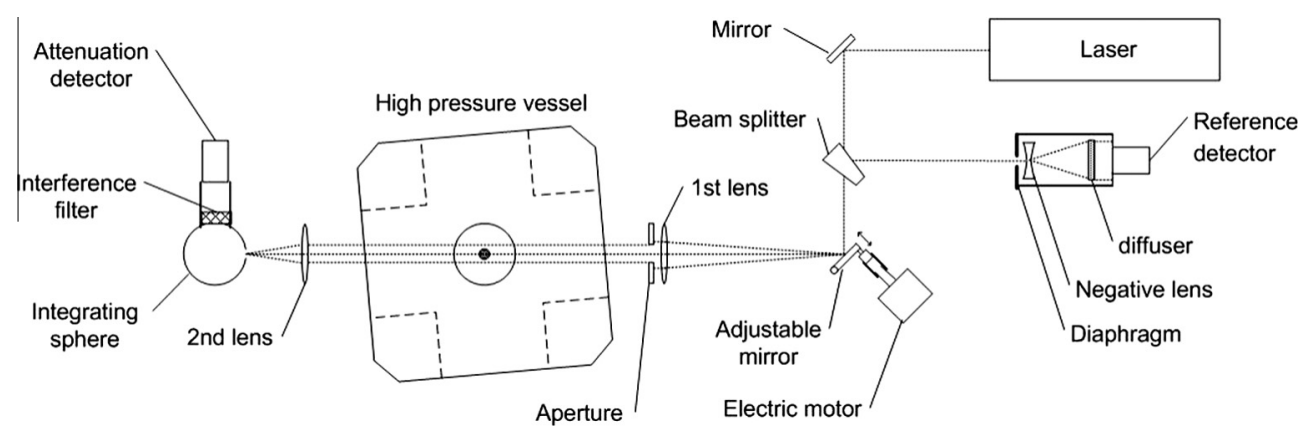

Fig. 4. Layout of the LOSA set-up [33].

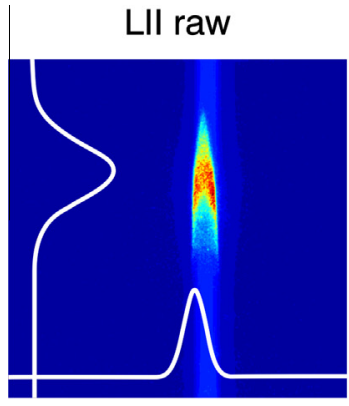

a

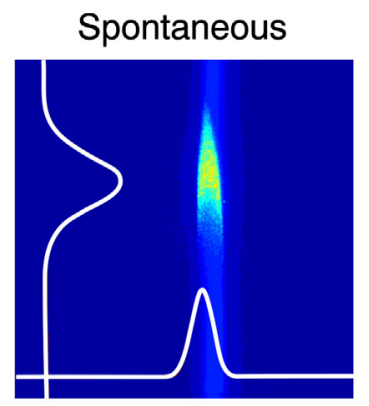

b

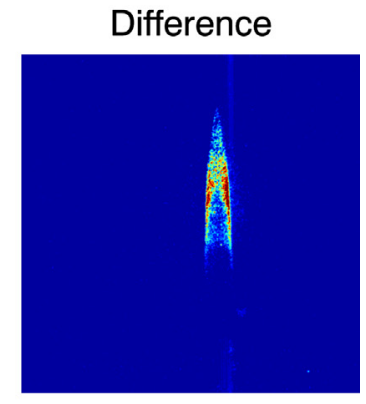

C

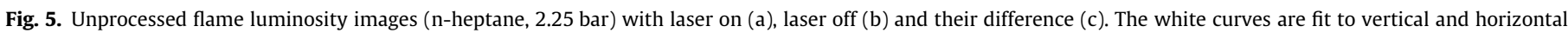

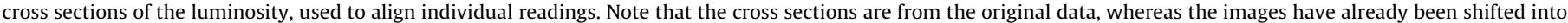
their standard position (see text).

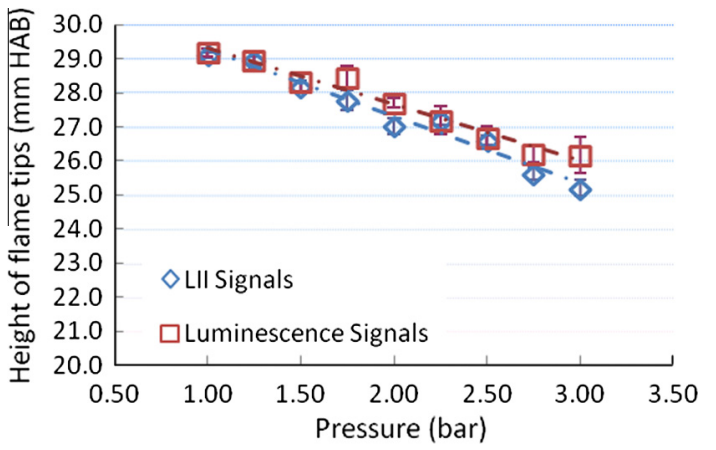

Fig. 6. Average flame tip height (maximum value of signals) with standard deviations of original LII signals and luminescence signals (n-heptane, ambient pressure $=1.0-3.0$ bar .

$[21,22]$. The LII radiation was focused onto the ICCD using an $\mathrm{f} / 2.8$ : $50 \mathrm{~mm}$ lens.

As shown in Fig. 4, the LOSA setup is designed to minimize disturbances [33]. The laser used for this research is a He-Ne laser, with a power of $5 \mathrm{~mW}$ and a wavelength of $632 \mathrm{~nm}$. To compensate for laser intensity variations, a reference detector is used. Making use of a wedge shaped beam splitter, approximately $4 \%$ of the laser intensity is split into the reference detector. The incident light intensity is determined from measurements outside the flame and the reference signals. A laser scan is created by an adjustable mirror and two positive anti-reflection coated lenses. The angle of the adjustable mirror can be changed with an electric step-motor. Since the mirror is located in the local point of the $1 \mathrm{st}$ lens, varying its angle changes the lateral position of the HeNe laser beam above the burner, but not its direction. Each scan covers more than the full flame width; start and end points are defined by an aperture. The HPVB is placed at an angle of $\sim 15^{\circ}$ with respect to the laser beam. This is done to prevent reflections along the laser beam.

\subsection{Measurement process}

During the measurement, the fuel flow rate of n-heptane is kept at $6.0 \mathrm{~g} / \mathrm{h}(1.67 \mathrm{mg} / \mathrm{s})$, the air co-flow is kept at $4.67 \mathrm{~g} / \mathrm{s}$ with fixed supply pressure of 8 bar and the carrier nitrogen is kept at $14 \mathrm{mg} / \mathrm{s}$ with fixed supply pressure of 10 bar. The mass flow fraction of fuel in the fuel mixture including nitrogen carrier gas is $11 \%$. Consequently, during the whole measurement process, as the boiling point of n-heptane is $99^{\circ} \mathrm{C}$ at $1 \mathrm{bar}$, the system temperature is kept at $180^{\circ} \mathrm{C}$ which is enough to guarantee full evaporation of n-heptane. Then, the mass flow rate of the fuel mixture in the tube and the co-flow around the tube are $1.25 \mathrm{mg} / \mathrm{mm}^{2} \mathrm{~s}$ and $2.41 \mathrm{mg} /$ $\mathrm{mm}^{2} \mathrm{~s}$ respectively. This indicates that mass flow rates of the fuel mixture and co-flow are of a same level. As a result and since the densities of both mixtures are similar because they consist mainly of nitrogen, the velocities are also similar. The velocity in the fuel mixture is lower, but it will increase to higher values than the co-flow velocity due to the temperature increase by combustion. It is therefore expected that instabilities induced by shear layer between fuel mixture and co-flow air are avoided in such a way.

The setting of ambient pressure in the vessel was varied from 1.0 bar to 3.0 bar. In the LII measurements, for each flame, both the LII and spontaneous luminescence signals are captured in five individual frames at $6 \mathrm{~s}$ interval LII images are based on single laser pulse.

In the LOSA measurements, the beam was slowly swept through the flame at a fixed Height Above Burner (HAB) (10 s per scan). Note that in the optical setup of Fig. 4, the HeNe beam hits the adjustable mirror on its rotation axis, and this axis lies in the focal plane of the first lens. In this way, by rotating the mirror, only the 

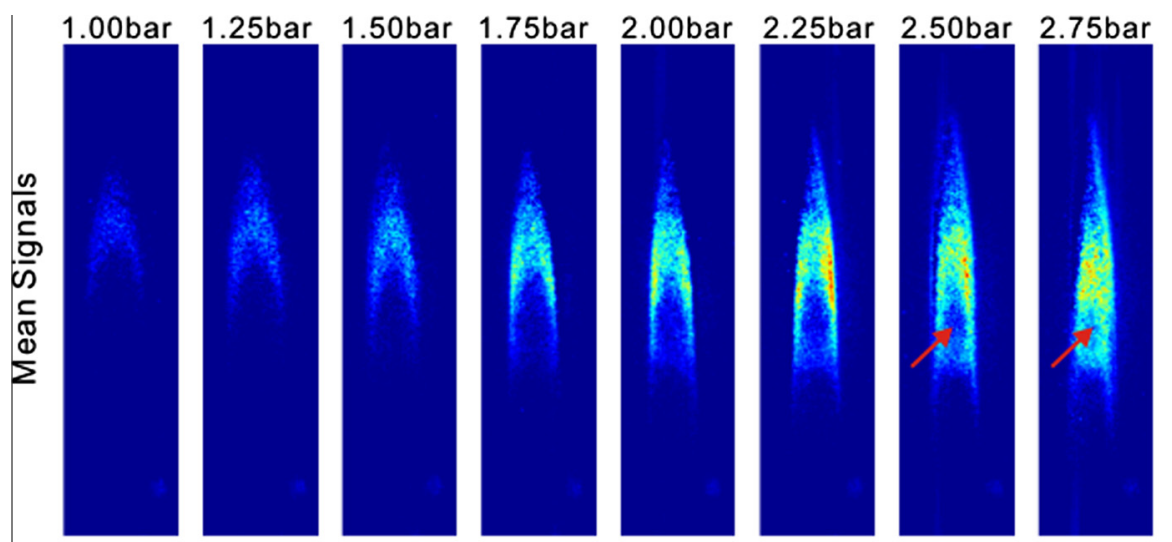

3.00bar
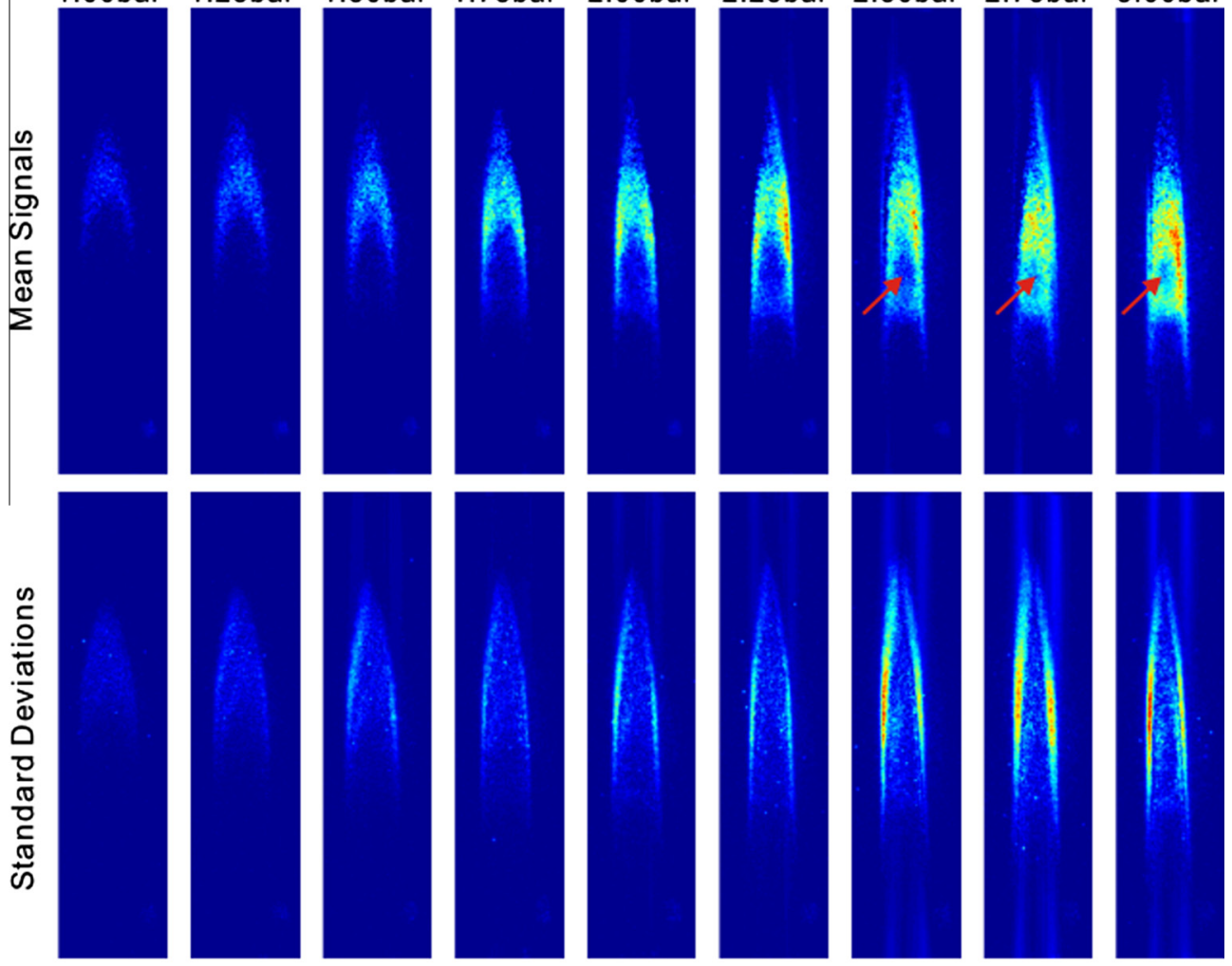

$\min$

LII signals (a.u.)

$\max$

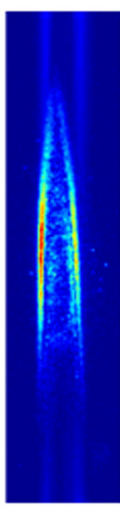

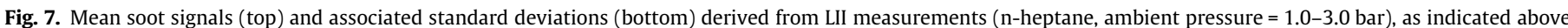

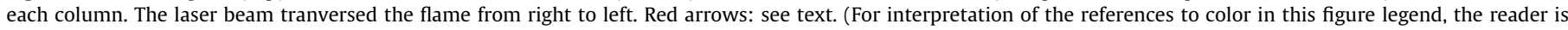
referred to the web version of this article.)

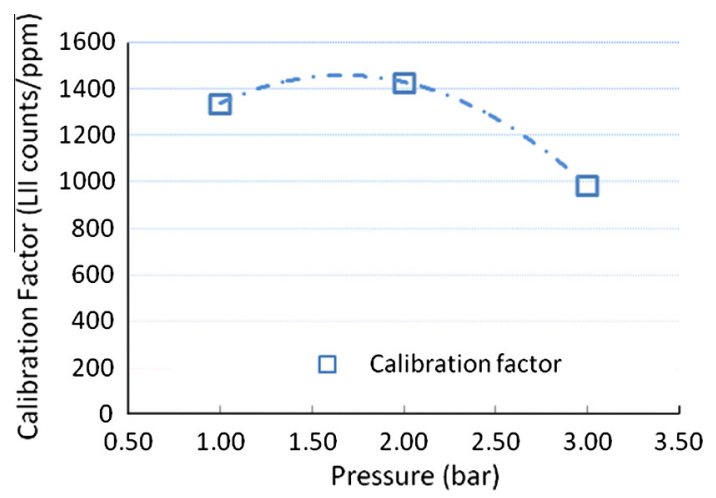

Fig. 8. Calibration factors between LII signals and soot volume fraction by LOSA ( $\mathrm{n}$ heptane, ambient pressure $=1.0-3.0$ bar .

location of the HeNe beam through the flame is varied, but not its direction. Scans were limited by a rectangular slit in front of the HPVB. The second lens focuses the transmitted light into a small integrating sphere, thus reducing the possible effects of beam steering by the flame. The transmitted and reference intensities were recorded by a sampling oscilloscope (LeCroy Waverunner $44 \mathrm{MXi}-\mathrm{A}$ ). Burner height was varied by translating the whole vessel up or down in steps of $1.52 \mathrm{~mm}$ for one full rotation. The laser beam was kept unchanged. Since this also implied that the laser beam had to pass through different parts of the entrance and exit windows, reference scans without a flame were recorded for every setting of the HAB. The extinction signal was calculated by subtracting the flame-on signal from the flame-off signal at the same
HAB. The reference signal was stable during all measurements. The original data required a small correction for non-uniform scan speed. The LOSA calibration factors for LII were determined at the positions of maximum soot concentration alone the centerline in the flames at $1.0 \mathrm{bar}, 2.0 \mathrm{bar}$ and $3.0 \mathrm{bar}$, respectively, using $k_{e}=9$, as mentioned earlier. The results were subsequently extrapolated to all other flames by interpolation.

\section{Results and discussions}

\subsection{Flame stability}

As mentioned in the first part of this paper, flame stability becomes an issue for measurements on laminar diffusion flames of liquid fuels at elevated pressures. In order to quantify the stability of our flames, we determined both the lateral position and height of the flame tips in all recordings made under nominally identical conditions. Figure 5 shows an example of the measurement data. Figure 5a is an unprocessed recording of the flame including LII signal (laser on; single shot), Fig. 5b is recorded with identical settings but without LII signal (laser off), the lower panel is their difference (laser on minus laser off), which we interpret as the actual LII signal. ${ }^{1}$

Obviously, the natural flame luminosity provides a dominant contribution to the signal, also when the laser induces additional

\footnotetext{
${ }^{1}$ We realize that it is a bit tricky to compensate the laser-heated part of the flame for natural luminosity as well (there is no natural luminosity in the laser-heated region any more). The thin light sheet in combination with the line-of-sight nature of the detection is expected to render the overcompensation negligible.
} 

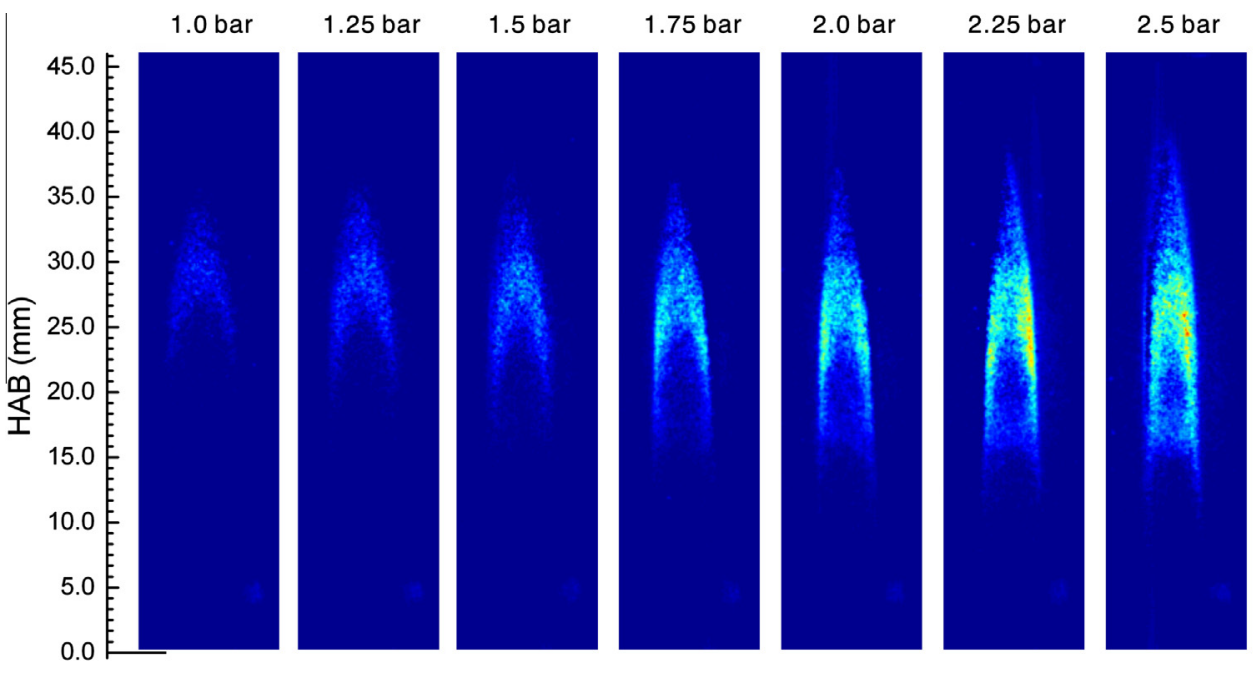

2.75 bar
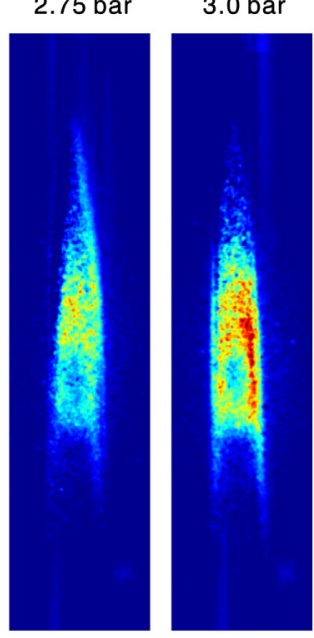

7.2

Soot Volume Fraction (ppm)

Fig. 9. Soot volume fraction of laminar diffusion flames ( $\mathrm{n}$-heptane, ambient pressure $=1.0-3.0$ bar). The laser beam tranversed the flame from right to left.

Table 1

The estimated pressure exponent in previous studies [6-10,12].

\begin{tabular}{cllll}
\hline Fuel & $\begin{array}{l}\text { Fuel flow rate } \\
(\mathrm{mg} / \mathrm{s})\end{array}$ & $\begin{array}{l}\text { Pressure } \\
(\mathrm{bar})\end{array}$ & $\begin{array}{l}\text { Pressure exponent } n \text { in } \\
\text { the } f_{v_{-} \max }=C p^{n}\end{array}$ & Refs. \\
\hline $\begin{array}{c}\text { Ethylene } \\
\left(\mathrm{C}_{2} \mathrm{H}_{4}\right)\end{array}$ & 3.4 & $1-4$ & 2 & {$[10,12]$} \\
Methane & 1.1 & $1-16$ & 1.7 & {$[10,12]$} \\
$\left(\mathrm{CH}_{4}\right)$ & 0.55 & $1-5$ & 1.2 & {$[6,8]$} \\
& 0.55 & $5-20$ & 2 & {$[6,8,12]$} \\
Propane & 0.49 & $20-40$ & 1.2 & {$[6,8,12]$} \\
$\left(\mathrm{C}_{3} \mathrm{H}_{8}\right)$ & & $1-7.3$ & 1.8 & {$[7]$} \\
Ethane & 0.52 & & & {$[9]$} \\
$\left(\mathrm{C}_{2} \mathrm{H}_{6}\right)$ & 0.52 & $2-5.1$ & 2.2 & {$[9]$} \\
& 0.52 & $5.1-15.2$ & 1.1 & {$[9]$} \\
& & $15.2-$ & 0.4 & \\
\hline
\end{tabular}

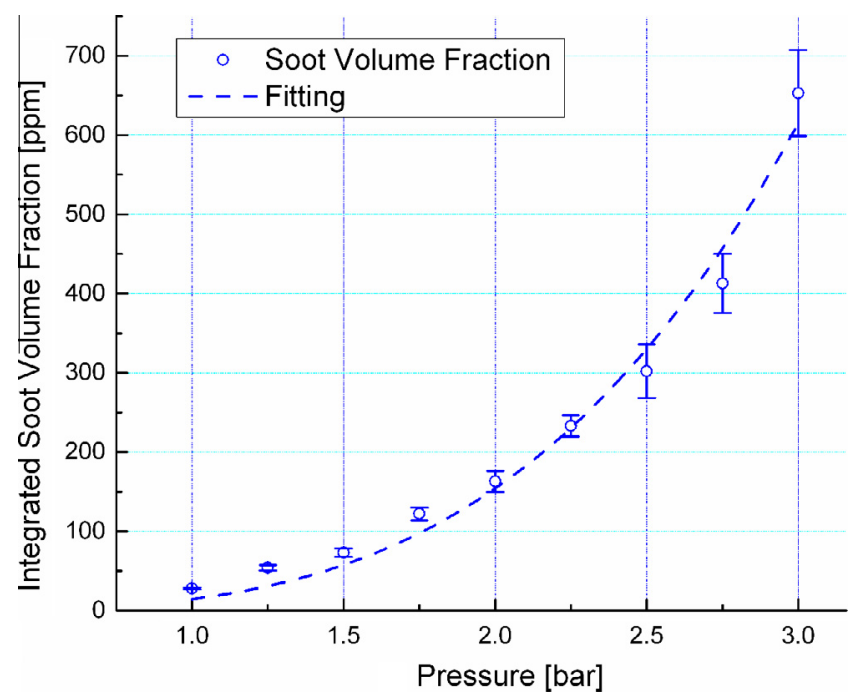

Fig. 10. Power law fit for integrated soot volume fraction (n-heptane, ambient pressure $=1.0-3.0$ bar)

incandescence. We have determined the flame position by fitting horizontal and vertical cross sections through these images to Gaussian profiles. For each setting, five individual single-shot images were collected, and these were, per setting, shifted to their average vertical position and, for all settings, to the same (arbitrary) horizontal position. Afterwards, the five background images were averaged, and then the LII contributions were evaluated by subtracting the "laser off" average from the individual "laser on" images (Fig. 5c).

In Fig. 6, we show the vertical position of the flame tips as a function of pressure for both the "laser on" and "laser off" measurements, with standard deviations $(\sigma)$ based on 5 replica's. The latter typically are smaller than $0.35 \mathrm{~mm}$ (about $2 \%$ of the flame height), but the fluctuations increase with pressure. Clearly, the flame tip height decreases with increasing pressure. The mass flow rate of the fuel might be gradually decreasing with pressure due to the difficulties for calibrating the mass flow while operating at high pressures, which is partly contribute to the lower height of the flame with the pressure. Moreover, somewhat unexpected, the natural luminosity shows a slightly higher flame than the LII pictures. This last observation must be treated cautiously because the soot temperature is a strongly non-linear factor in the luminosity yield [35]. Note that it cannot be due to insufficient laser sheet height, because at 1.0 bar the LII-tip is highest, Fig. 12 shows that there are no obvious non-uniformities.

However that may be the soot which shows luminescence by itself is also expected to be superheated by the laser pulse, and there is no obvious reason why the "laser on" flame images should be less high than the "laser off" ones. Such a region might contribute little to the natural luminosity, but would show up strongly after laser heating. The occurrence of such a region implies that with increasing pressure, either the soot formation rate decreases towards the flame tip, or the soot oxidation rate in the same region increases and as a result the soot formation decreases.

\subsection{Soot formation}

\subsubsection{LII soot signals}

For all ambient pressures considered in this study, Fig. 7 shows the average LII distribution (i.e., soot volume fractions) and their standard deviations (based on pixel-by-pixel evaluation of the five individual images). The scale is the same for all images, so they can be compared amongst each other. According to Fig. 7, soot production increases with increasing pressure while the flame stability decreases with increasing pressure. Moreover, the flame stretches 


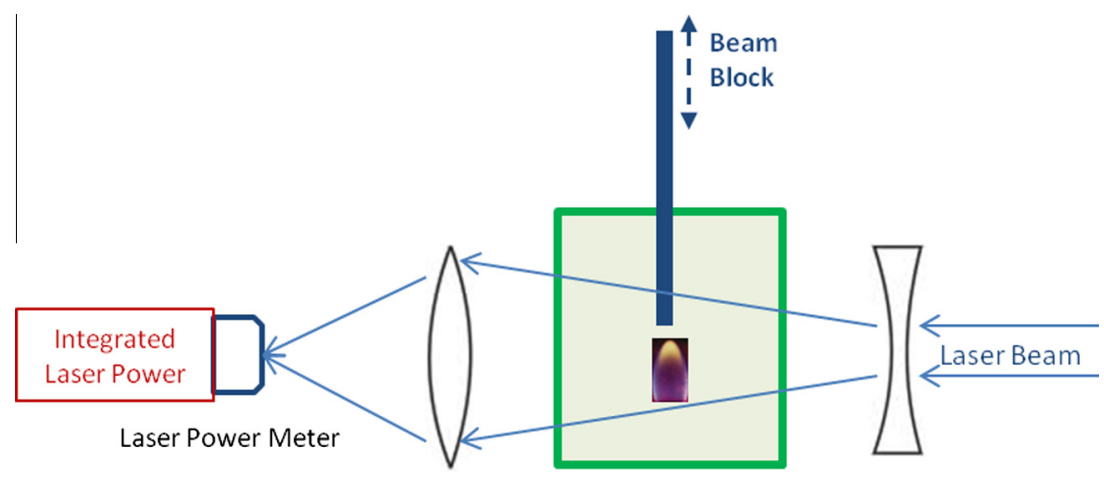

Fig. 11. Laser power measurement.

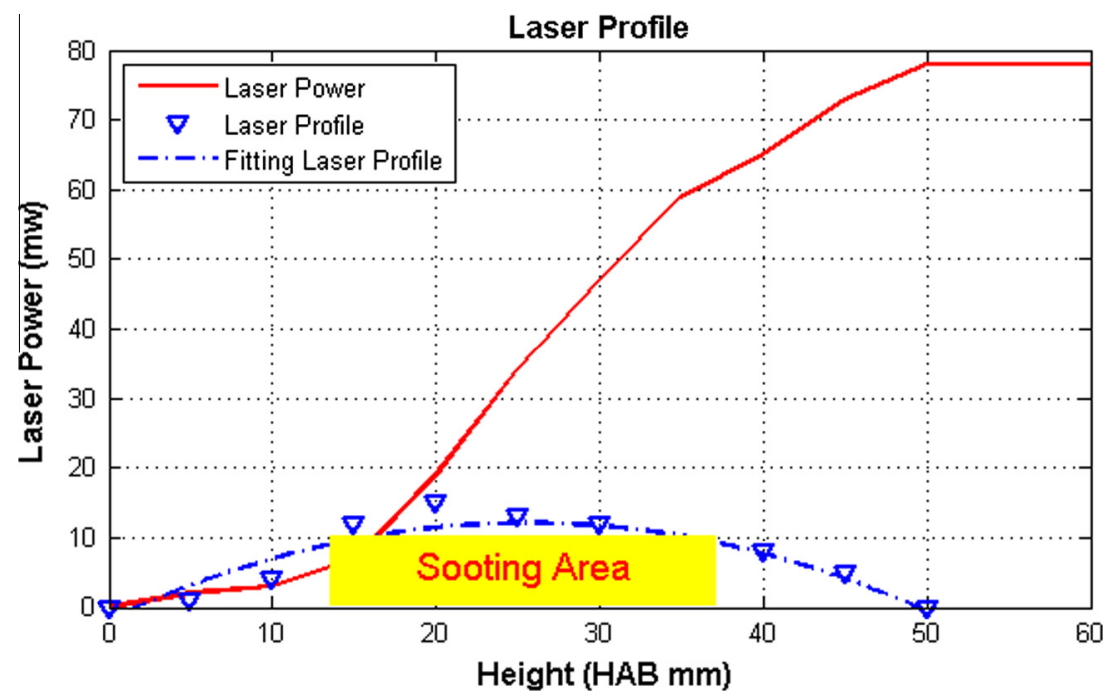

Fig. 12. Laser profile.

Table 2

Fitting results of Fig. 10.

\begin{tabular}{lll}
\hline & Value & Standard error \\
\hline$a$ & 14.480 & 3.800 \\
$b$ & 3.412 & 0.258 \\
\hline
\end{tabular}

downward with increasing pressure, and also becomes a bit narrower. It should be noticed that a pocket of low soot density seems to grow into the upper part of the flame (see red arrows in Fig. 7; this is not a laser absorption effect, since the region is surrounded by high-signal regions). The standard deviation is relatively high, which might be attributed to the subtraction of two large numbers. The asymmetry of the soot signals increases with pressure likely due to laser absorption occurs while the laser passes through the flame from right to left.

\subsubsection{Calibration by LOSA}

The primary use of the extinction data in this study was to calibrate the LII data, so three representative conditions of $1.0 \mathrm{bar}$, 2.0 bar and 3.0 bar have been selected for this calibration.

However, the absorption profiles by the LOSA concept relate to a line-of-sight integrated soot density at each height, whereas the LII data are a measure for the local soot density at each point. Therefore, there are two routes for the calibration of LII signals by LOSA signals. The first route involves transforming the integrated LOSA signals to local soot signals [13-15]. By this method, the tangential extinction profiles have to be transformed using
Abel inversion [36] for calculation of radial soot volume fractions. As a prerequisite for this process, the LOSA profiles have to be made symmetric, which may introduce an error source into the final results. The second route uses the maximum signals at the centerline from the LOSA measurement to calculate the calibration factors by comparing them with the integrated LII signal at the corresponding height. This not only minimizes the uncertainties and errors, which could be dominating in the low sooting flames as the total extinction is very weak, but also allows for the possibility that the real soot distribution is not completely symmetric. The second route will be used for the soot volume fraction calibration in this research. As shown in Fig. 8, the value for the calibration factors between LII intensity and soot volume fraction from LOSA various slightly with pressure. Thus, the calibration factors in this paper have been taken at the corresponding interpolated value from the fitting curve shown in Fig. 8.

\subsubsection{Soot volume faction}

Figure 9 displays the soot volume fractions derived from the LOSA-calibrated LII measurements, for all pressures considered here. In the lower part of the flame, the soot forms kind of an annular zone. With increasing pressure, this ring zone descends and the amount of soot increases. Simultaneously, the flame tip height decreases, and the net result is that the sooting region increases in height. Some asymmetry can be observed (possible partly due to absorption of the laser beam), but this is not very constant. Also, 
the flame narrows a bit with increasing pressure, and becomes slightly constricted below the most strongly sooting region.

The flame height decreases slightly with the pressure (also mentioned in Fig. 6). This is somewhat at variance with theoretical considerations [37-41], which suggest that the height of a diffusion flame fed by fuel at a constant mass flow rate should be invariant with pressure. This prediction, however, is intended for laminar diffusion flames of gaseous fuels [6-12], and has not been validated for flames of vaporized liquid fuel. Due to the unavailability of the corresponding reference and the limit of measurement points (the measurement could only be realized up to 3 bar), we speculated that the following two factors might contribute to this phenomenon. First, a systematical error of the flames due to the evaporation process of the liquid fuel in Controlled Evaporator Mixer (CEM) or in the Mass Flow Controller (MFC). Second, with respect to the cases in gaseous fuels, because the higher quantity of the water production while burning the liquid fuels, the density of the gases inside the vessel is higher.

In related previous studies, apart from illustrations of visible flame height and cross sectional area, the maximum soot volume fraction has frequently been expressed in an approximate powerlaw relationship with pressure, that is, Soot volume fraction $f_{v_{-} \max }=C p^{n}$, in which $C$ is a proportionality constant and $n$ is the so called pressure exponent. As shown in Table $1, n$ is in the range from 0.4 to 2.2 , between 1 and 40 bar for most of the available data [6-10]. The value of $n$ is likely to depend on several factors, such as the fuel flow rate, pressure range, and fuel properties.

In our case, the location of maximum soot concentration varies considerably with pressure, and it does not seem reasonable to compare these values. Instead, we have taken the integrated soot volume fraction (integration on whole area of 2-D flames), as shown in Fig. 10 . The data can be fitted to $f_{v_{-} \text {integrated }}=C p^{n}$, resulting in a pressure exponent $n=3.4 \pm 0.3$ ( 1 -3 bar ambient pressure; fuel flow rate $1.67 \mathrm{mg} / \mathrm{s}$ ). The error bars are standard deviations derived from five individual single-shot images. In addition, the fitting process has been summarized in Appendix A.

\section{Conclusions}

Soot volume fraction measurements have been conducted in laminar diffusion flames with a liquid fuel, n-heptane, over a pressure range spanning from 1.0 to 3.0 bar. The mass flow rate of nheptane was kept constant at all pressures. LII was employed to measure soot volume fraction and has been calibrated by LOSA. The conclusions obtained from this research are summarized below:

(1) Up to 3 bar, the oscillations of the flame tips increase with pressure. The oscillations of the height of the flame tips were less than $1 \mathrm{~mm}$ in this setup.

(2) The flame tip height based on soot structure decreases slightly with increasing pressure, and, somewhat unexpected, the natural luminosity shows a slightly higher flame than the LII signals.

(3) The flame stretches downward with increasing pressure and also becomes a bit narrower. Moreover, a pocket of low soot density seems to grow into the center part of the flame. In the lower part of the flame, the maximum soot volume fractions gradually appear in an annular wing region for all investigated pressures.

(4) The axial position of peak soot formation decreases with pressure. This is not completely consistent with observations on laminar diffusion flames with gaseous fuels in other studies [6-12], where heights differ less.
(5) The value of the calibration factor between LII intensities and soot volume fraction from LOSA slightly changes with pressure.

(6) The integral soot volume fractions show a power law dependence with pressure. The measured integrated soot volume fraction is proportional to $p^{n}$, with $n$ being $3.4 \pm 0.3$ in the pressure range of 1.0-3.0 bar.

This initial research demonstrates the feasibility and capability of soot formation measurements on laminar diffusion flames with liquid fuels by means of laser diagnostics. Investigation of different chemical compounds by using other liquid fuels will shed more insight into the effects of molecular structures on the soot formation of laminar diffusion flames at elevated pressure.

\section{Acknowledgments}

The authors thank the European Graduate School on Sustainable Energy (http://www.egs-energy.eu/home) and KIC InnoEnergy for financial support of this project. The authors wish to acknowledge the former user of this HPVB: Dr. Marcelo de Oliveira and the technicians of the Eindhoven Combustion Technology group: Paul Bloemen, Hans van Griensven, Theo de Groot and Gerard van Hout, for their support with the measurements.

\section{Appendix A}

\section{A.1. Laser profile}

As shown in Fig. 11. In order to evaluate the errors brought about by the varying power of the laser over the height, the laser profile has been measured by a cylindrical lens and laser power meter behind the vessel. According to the results (see Fig. 12), the sooting area could be completely covered by the major part of the laser profile, where the deviations of the laser power is less than $5 \%$.

\section{A.2. Data fitting (Fig. 10)}

Iteration Algorithm: Levenberg-Marquardt algorithm (by Origin 9.0).

Number of points: 9; equation: $y=a x^{\mathrm{b}}$.

Fitting results:

Table 2

Fit status: Fit converged. Chi-Sqr tolerance value of 1e-9 was reached.

\section{References}

[1] T. Kadota, H. Hiroyasu, A. Farazandehmehr, Combust. Flame 29 (1977) 67-75.

[2] B.A. Fischer, J.B. Moss, Combust. Sci. Technol. 138 (1998) 43-61.

[3] T. Heidermann, H. Jander, H.G. Wagner, J. Phys. Chem. Chem. Phys. (1999) 497502.

[4] K.A. Thomson, PhD Thesis, University of Waterloo, 2004.

[5] J.B. Moss, C.D. Stewart, K.J. Syed, Technical Report, Cranfield Institute of Technology, 1988.

[6] K.A. Thomson, Ö.L. Gülder, E.J. Weckman, R.A. Fraser, G.J. Smallwood, D.R. Snelling, Combust. Flame 140 (2005) 222-232.

[7] D.S. Bento, K.A. Thomson, Ö.L. Gülder, Combust. Flame 145 (2006) 765-778.

[8] H.I. Joo, Ö.L. Gülder, Proc. Combust. Inst. 32 (2009) 769-775.

[9] P.M. Mandatori, Ö.L. Gülder, Proc. Combust. Inst. 33 (2011) 577-584.

[10] M.R.J. Charest, C.P.T. Groth, Ö.L. Gülder, Combust. Flame 158 (2011) 860-875

[11] Ö.L. Gülder, G. Intasopa, H.I. Joo, P.M. Mandatori, D.S. Bento, M.E. Vaillancourt, Combust. Flame 158 (2011) 2037-2044.

[12] L.L. McCrain, W.L. Roberts, Combust. Flame 140 (2005) 60-69.

[13] M.D. Smooke, M.B. Long, B.C. Connelly, M.B. Colket, R.J. Hall, Combust. Flame 143 (2005) 613-628.

[14] A.V. Menon, PhD Thesis, Pennsylvania State University, 2010.

[15] A.G. Mouis, A. Menon, V. Katta, T.A. Litzinger, M. Linevsky, R.J. Santoro, S.P. Zeppieri, M.B. Colket, W.M. Roquemore, Combust. Flame 159 (2012) 31683178. 
[16] A.E. Karatas, Ö.L. Gülder, Prog. Energy Combust. Sci. 38 (2012) 818-845.

[17] H.G. Darabkhani, J. Bassi, H.W. Huang, Y. Zhang, Fuel 88 (2009) 264-271.

[18] H.G. Darabkhani, PhD Thesis, University of Manchester, 2010.

[19] C. Schulz, B.F. Kock, M. Hofmann, H.A. Michelsen, S. Will, B. Bougie, R. Suntz, G.J. Smallwood, Appl. Phys. B 83 (2006) 333-354.

[20] H.A. Michelsen, J. Chem. Phys. 118 (2003) 7012-7045.

[21] A. Melton, Appl. Opt. 23 (1984) 2201-2208.

[22] B. Quay, T.-W. Lee, T. Ni, R.J. Santoro, Combust. Flame 97 (1994) 384-392.

[23] J. Bassi, M. Naftaly, B. Miles, Y. Zhang, Flow Measur. Instrum. 16 (2005) 341345.

[24] F. Migliorini, S. De Iuliis, F. Cignoli, G. Zizak, Appl. Opt. 45 (29) (2006) 77067711.

[25] C.R. Shaddix, K.C. Smyth, Combust. Flame 107 (1996) 418-452.

[26] F. Liu, K.A. Thomson, G.J. Smallwood, J. Quan. Spectro. Radia. Trans., 2007.

[27] R. Lemaire, A. Faccinetto, E. Therssen, M. Ziskind, C. Focsa, P. Desgroux, Proc. Combust. Inst. 32 (2009) 737-744.

[28] M.Y. Choi, K.A. Jensen, Combust. Flame 112 (1998) 485-491.

[29] D.R. Snelling, K.A. Thomson, G.J. Smallwood, O.L. Gulder, Appl. Opt. 38 (1999) $12-20$.
[30] S.S. Krishnan, K.C. Lin, G.M. Faeth, J. Heat Transfer. 123 (2001) 331-339.

[31] S.S. Krishnan, K.C. Lin, G.M. Faeth, J. Heat Transfer. 122 (2000) 517-524.

[32] M. Hofmann, W.G. Bessler, C. Schulz, H. Jander, Appl. Opt. 42 (12) (2003) 2052 2062

[33] M.H. de Andrade Oliveira, $\mathrm{PhD}$ Thesis, Technische Universiteit Eindhoven 2012. <http://alexandria.tue.nl/extra2/732108.pdf>.

[34] I.M. Miller, H.G. Maahs, NASA Technical Paper, TN D-8407, 1977.

[35] A.J. Donkerbroek, M.D. Boot, C.C.M. Luijten, N.J. Dam, J.J. ter Meulen, Combust. Flame 158 (2011) 525-538.

[36] C.J. Dasch, Appl. Opt. 31 (8) (1992) 1146-1152.

[37] W.L. Flower, C.T. Bowman, Proc. Combust. Inst. 21 (1986) 1115-1124.

[38] F.G. Roper, Combust. Flame. 29 (1977) 219-226.

[39] F.G. Roper, C. Smith, A.C. Cunningham, Combust. Flame 29 (1977) 227-234.

[40] R.W. Davis, E.F. Moore, R.J. Santoro, J.R. Ness, Combust. Sci. Technol. 73 (1990) 625-635.

[41] C.H. Kim, F. Xub, G.M. Faeth, Combust. Flame 152 (2008) 301-316. 